\title{
Caracterização do cascalho de perfuração dos poços de petróleo da bacia Sergipe-Alagoas para produção de concreto permeável
}

A revolução industrial trouxe progresso e desenvolvimento, mas também promoveu aumento do consumo de bens naturais e a consequente geração de resíduos. O cascalho de perfuração faz parte desses resíduos que, quando disposto inadequadamente, pode gerar impactos ambientais através da poluição atmosférica, poluição hídrica, poluição do solo e poluição visual, bem como pode causar doenças para população, ocasionando dano a saúde das pessoas. Gerado das diferentes explorações de poços de petróleo e gás que, anualmente, produzem milhões de toneladas - e derivado da geração de petróleo, após a escavação de poços - o cascalho pode ser definido como fragmentos de rochas e fluido provenientes dessa perfuração. Este trabalho objetivou caracterizar o cascalho proveniente da bacia Sergipe-Alagoas de forma física, química e morfológica, visando aplicação em concretos permeáveis. Os ensaios realizados foram de Análise Granulométrica, Microscopia Eletrônica de Varredura, Fluorescência de Raios X, Difração de Raios X e Análises Térmicas. Como resultados, constatou-se que o material analisado apresentava pequena quantidade de finos, tendo aproximadamente $80 \%$ do cascalho com diâmetro superior a $0,6 \mathrm{~mm}$. Identificou-se que o material apresenta aspecto estrutural característico das argilas, com estrutura lamelar, tipicamente encontrada em perfurações de poços nacionais, com aspecto maciço, compactado e endurecido, possuindo alto teor de cálcio e que, quando submetido a temperaturas de até $1000^{\circ} \mathrm{C}$, perde cerca de $14 \%$ da massa total.

Palavras-chave: Indústria do petróleo; Perfuração de poços; Cascalho.

\section{Characterization of drilling gravel of oil wells in the Sergipe-Alagoas basin for the production of permeable concrete}

The industrial revolution brought progress and development, but also promoted an increase in the consumption of natural goods and the consequent generation of waste. Drilling gravel is part of this waste that, when disposed of improperly, can generate environmental impacts through air pollution, water pollution, soil pollution and visual pollution, as well as it can cause diseases to the population, causing damage to people's health. Generated from different explorations of oil and gas wells that annually produce millions of tons - and derived from the generation of oil after the excavation of wells - gravel can be defined as fragments of rocks and fluid from this drilling. This work aimed to characterize the gravel from the Sergipe-Alagoas basin in physical, chemical and morphological form, aiming at application in permeable concrete. The tests performed were Granulometric Analysis, Scanning Electron Microscopy, X-Ray Fluorescence and X-Ray Diffraction. As a result, it was found that the analyzed material had a small amount of fines, with approximately $80 \%$ of the gravel with a diameter greater than 0.6 mm. It was identified that the material has a structural aspect characteristic of clays, with lamellar structure, typically found in national well drilling, with a solid, compacted and hardened aspect, having a high $\mathrm{CaO}$ content and which, when subjected to temperatures up to $1000^{\circ} \mathrm{C}$, loses about $14 \%$ of the total mass.

Keywords: Oil industry; Drilling of wells; Grave.

Topic: Notas Científicas

Reviewed anonymously in the process of blind peer
Received: 06/07/2021

Approved: 29/07/2021
José Diôgo Barbosa de Almeida (iD) Instituto Federal de Alagoas, Brasil http://lattes.cnpq.br/4812351752021535

http://orcid.org/0000-0002-3930-2060

diogo.barbosa@ifal.edu.br

Áurea Luiza Quixabeira Rosa e Silva Rapôso (iD

Instituto Federal de Alagoas, Brasil

http://lattes.cnpq.br/7600867517446003

http://orcid.org/0000-0002-2699-9778

aurea.raposo@ifal.edu.br

Sheyla Karolina Justino Marques (it)

Instituto Federal de Alagoas, Brasil

http://lattes.cnpq.br/3917387578549073

http://orcid.org/0000-0001-7554-2275

sheyla.marques@ifal.edu.br
Referencing this:

ALMEIDA, J. D. B.; RAPÔSO, Á. L. Q. R. S.; MARQUES, S. K. J.

Caracterização do cascalho de perfuração dos poços de petróleo da bacia Sergipe-Alagoas para produção de concreto permeável. Revista Ibero Americana de Ciências Ambientais, v.12, n.7, p.585-598, 2021. DOI: http://doi.org/10.6008/CBPC2179-6858.2021.007.0050 


\section{INTRODUÇÃO}

A revolução industrial trouxe mudanças significativas para a sociedade atual e contribuiu diretamente para o surgimento da revolução tecnológica vivida até hoje (ROCHA et al., 2020). É certo que a globalização trouxe progresso e rompeu barreiras, o que melhorou a formação e a tecnologia no mundo, mas também promoveu aumento do consumo de bens naturais e a consequente geração de resíduos, que geralmente são constituídos por elementos de difícil decomposição (LEITE et al., 2006; SOUZA et al., 2016).

Esses resíduos, tratados nesse estudo como subprodutos, ou seja, matérias-primas não processadas que apresentam capacidade de reutilização enquanto insumos secundários -, quando dispostos inadequadamente, podem gerar impactos ambientais através da poluição atmosférica, poluição hídrica, poluição do solo e poluição visual; e, além disso, podem causar doenças para população, ocasionando dano a saúde das pessoas. Para amenizar esses impactos, utiliza-se da incorporação de subprodutos que seriam descartados no desenvolvimento de novos materiais e produtos que seriam descartados, contribuindo para a redução da poluição e para a preservação dos recursos naturais, além da economia de energia e redução do volume de aterros (JOHN, 2000; LOMASSO et al., 2015).

O cascalho de perfuração é gerado das diferentes explorações de poços de petróleo e gás e, anualmente, produzem milhões de toneladas desse subproduto que precisa ser adequadamente gerenciado e armazenado, na maioria das vezes, dentro da própria empresa (ACCHAR et al., 2016; MARQUES, 2015). Esse material pode ser definido como fragmentos de rochas e fluido provenientes da perfuração, podendo conter fragmentos de cimento curado na composição (ALMEIDA, 2016).

A produção de petróleo consiste em atividade exploratória que gera diversos riscos. Entre eles, está a geração de grande quantidade de cascalho, que são depositados na superfície dos solos, sem o devido tratamento. Por ser atividade que atinge diretamente a preservação dos recursos naturais, uma vez que quanto maior o crescimento da exploração maior será a necessidade de áreas para deposição do material gerado, faz-se necessário obter-se solução efetiva na destinação do cascalho gerado, de forma que se minimize os impactos causados por essa atividade (MENESES et al., 2015; MARTINS et al., 2015).

Incorporar subprodutos em novos materiais consiste em alternativa de mitigar esses impactos e o concreto permeável pode fazer parte dessa solução. Ele ganhou importância nos últimos anos como material de revestimento para aplicação em pavimentos. Diferentemente dos pavimentos tradicionais, os pavimentos permeáveis permitem a infiltração da água pluvial na superfície, além de controlar o escoamento superficial e a degradação da qualidade da água. Deste modo, o concreto permeável caracteriza-se como importante mecanismo para minimizar os problemas das grandes cidades, evitar inundações e, neste caso, incorporar cascalho de perfuração na composição (ANTUNES, 2017).

O objetivo deste trabalho foi caracterizar o cascalho proveniente da bacia Sergipe-Alagoas de forma física, química e morfológica, visando aplicação em concretos permeáveis, como alternativa para recuperação e destinação. $O$ artigo encontra-se organizado em 5 seções: Introdução, Referencial Teórico, Materiais e Métodos, Resultados e Discussão e Conclusão. A primeira seção apresenta contextualização, o 
porquê da escolha desta pesquisa e o objetivo do trabalho. A segunda seção faz abordagem teórica do cascalho de perfuração, desde a exploração do petróleo até o descarte dos resíduos, além de apresentar, na subseção Informações sobre o concreto permeável. A terceira seção apresenta os Materiais e Métodos, acentuando a obtenção do subproduto, os ensaios e os equipamentos utilizados na caracterização. Na quarta seção são expostos os resultados e as discussões; e, na quinta seção, apresentam-se as conclusões do trabalho.

\section{REVISÃO TEÓRICA}

\section{Exploração e cadeia produtiva da indústria petrolífera}

A Exploração e Produção (E\&P) integram a base da indústria petrolífera como os primeiros passos para a obtenção do Petróleo. Grandes investimentos são despendidos no desenvolvimento tecnológico, na ampliação dos conhecimentos geológicos e na formação da cadeia de bens e serviços que dê suporte à atividade exploratória (FAGUNDES, 2018).

Essa E\&P se configuram, basicamente, por dois ambientes de perfuração: as explorações em águas profundas, também denominadas offshores; e, as explorações em terra, denominadas onshore. As perfurações offshore, de maneira geral, sintetizam todo o processo em três conjuntos tecnológicos distintos que, por sua vez, são os objetos de pesquisa das companhias: as plataformas, o sistema de perfuração e o mecanismo de transmissão do petróleo da profundeza para a plataforma (ORTIZ NETO et al., 2007).

A E\&P teve início no final do século XIX, em perfurações de até 30 metros (águas ultrarasas), de maneira rudimentar e pouco científica. Isso porque as dificuldades tecnológicas eram superadas de maneira empírica. Na verdade, era transferido para a exploração offshore o mesmo padrão tecnológico utilizado no segmento onshore. Com a ampliação das descobertas e o consequente aumento das dificuldades de exploração em campos mais profundos (águas rasas - entre 30 e 400 metros) e mais distantes da costa, foi necessário o desenvolvimento de procedimentos e tecnologias próprias, não sendo mais utilizada a rudimentar e empírica adaptação de equipamentos onshore. Dessa forma, foram construídas as primeiras plataformas fixas, necessitando de equipamentos mais modernos. Iniciava-se, assim, a busca de trajetória tecnológica, que viabilizasse a exploração offshore em mar aberto (ORTIZ NETO et al., 2008).

Para que se chegue à produção de diferentes poços, a perfuração é realizada por sonda, constituída por vários sistemas com funções específicas. As perfurações acontecem, principalmente, por meio de dois métodos de perfuração: à percussão e rotativo. No método à percussão, são deferidos golpes por broca pontiaguda, gerando o esmagamento da rocha. Já no método rotativo, adota-se tecnologia diferente; neste, a broca é girada e comprimida sobre o solo e as rochas, que se fragmentam. A energia necessária para perfurar as diversas formações rochosas é proveniente do movimento de rotação e cargas aplicadas sobre a broca que, quando transferidas às rochas, promovem ruptura e desagregação em forma de pequenas lascas ou cascalhos, que são removidos do fundo do poço e carreados até a superfície pelo fluxo do fluído de perfuração (BANDEIRA, 2019). 
Como as escavações são de grandes profundidades, podendo chegar a $6 \mathrm{~km}$, a perfuração acontece por fases. Ao atingir determinada profundidade, a coluna de perfuração é retirada e se insere coluna de revestimento de aço, de diâmetro inferior ao da broca. O número de fases e o comprimento das colunas de revestimento são determinados em função das pressões e fratura previstas (FAGUNDES, 2018).

Segundo Fagundes (2018), essa divisão de fases e diferentes colunas de revestimento têm a função de "[...] prevenir o desmoronamento das paredes do poço, evitar contaminação da água potável dos lençóis freáticos, permitir o retorno do fluído [sic] de perfuração à superfície, impedir a migração de fluido das formações para o interior do poço, etc [...]".

Para auxiliar na perfuração, faz-se necessário se utilizar dos fluidos de perfuração, em cujas formulações químicas são adicionados diferentes produtos químicos e materiais sólidos, a fim de se alcançar composição com propriedades específicas, necessárias para as operações de perfuração de poços petrolíferos. A classificação do fluido de perfuração é feita em função da composição e do tipo de fase líquida. Nesse critério, classificam-se os fluidos em: de base aquosa e de base não aquosa, também denominados como fluidos a base de óleo. Há ainda a utilização de gás, que pode ser ar ou gás natural, além de lamas aeradas (normalmente com nitrogênio); no entanto, a utilização é restrita a cenários específicos (PEREIRA, 2010; ALMEIDA, 2016).

Os fluidos mais utilizados na indústria são os de base aquosa, pois apresentam fácil manipulação, baixo custo de manutenção e podem ser formulados para superar diversos problemas de perfuração, causando menor impacto ambiental em relação aos fluidos não aquosos. Os fluidos aquosos tratam-se de formulações compostas por $50 \%$ a $90 \%$ de água, com adição de argilas, polímeros, agentes adensantes, sais inorgânicos e outros aditivos dissolvidos ou em suspensão (RIBEIRO, 2015).

\section{Cascalho de perfuração de poços de petróleo}

A indústria de petróleo e gás gera vários produtos e com eles inúmeros subprodutos. Um dos principais subprodutos da atividade de perfuração de poços de petróleo e gás são os cascalhos de perfuração. A perfuração de poços de petróleo ocorre em duas fases: a de exploração e a de desenvolvimento. Para que se localizem as reservas de hidrocarbonetos, existe perfuração prévia chamada de atividades de exploração. Nessa fase, identifica-se o potencial produtivo das reservas de hidrocarbonetos e o potencial econômico. Quando essas reservas já foram descobertas, surge a fase de desenvolvimento, que busca o usufruto do material encontrado. Nas duas fases há geração de cascalho (PIRES, 2009).

A perfuração divide-se em diferentes estágios e diminui o diâmetro do poço à medida que aumenta a altura dessa escavação, proporcionando a menor geração de subprodutos por metro perfurado (ALMEIDA NETO, 2017). O volume de cascalho produzido durante a escavação varia, visto que a quantidade produzida é proporcional à profundidade, ao diâmetro e às características geológicas das formações perfuradas. Nesse processo, o volume gerado tende a ser o volume geométrico do cilindro perfurado somado ao fluido de perfuração (PIRES, 2009).

O Brasil tem apresentado grande geração desse subproduto. Nicolli et al. (2010) consideram que, em 
média, 1 poço gera entre 500 e $800 \mathrm{~m}^{3}$ de material resultante da trituração das rochas pela broca. Fialho (2012), a partir de dados de perfurações terrestres, obtidos para o ano de 2010 no Estado do Espírito Santo, apresenta a geração média de $13 \mathrm{~m}^{3}$ de cascalho a cada 100 metros perfurados.

Segundo Almeida Neto (2017), só no nordeste estima-se que exista, atualmente, quantidade de subprodutos da ordem de 100 mil $\mathrm{m}^{3}$ oriundos do processo de perfuração de poços para produção de petróleo. Quantidade significativa, principalmente, por saber que os cascalhos, quando dispostos inadequadamente, poluem o solo, deteriora a paisagem urbana e constituem passivo ambiental, caso sejam destinados a aterros sem tratamento prévio (FIALHO, 2012).

Vários são os trabalhos que tratam do reaproveitamento do cascalho. Pires (2009) utilizou do cascalho para produção de cerâmica vermelha; Fialho (2012) aplicou cascalho para a produção de concreto convencional; Shon et al. (2016) aplicou esse subproduto em contruções de estradas; Almeida Neto (2017) usou do cascalho para elaborar argamassa de cimentação primária com vistas à inserção em novos poços; e muitos outros trabalhos que tiveram resultados satisfatórios, positivando a substituição.

\section{Concreto permeável}

O concreto permeável é o tipo de concreto que apresenta maior volume de vazios. É caracterizado por possuir elevada porosidade e boa drenabilidade, sendo composto por ligante hidráulico, material britado de graduação uniforme, água e pouca ou nenhuma quantidade de agregado miúdo. Na composição pode-se utilizar combinação de diferentes tipos de adições e aditivos, que possuem a finalidade de atribuir ao concreto melhor desempenho, durabilidade, resistência e trabalhabilidade (BATEZINI, 2013).

Essencialmente, pode-se dizer que o concreto permeável difere do concreto convencional pelo elevado índice de vazios. Nos concretos convencionais o objetivo é o alcance da maior densidade possível, já que os concretos permeáveis devem conter poros para permitir a infiltração de água (LAMB, 2014).

Os concretos permeáveis destinam-se, basicamente, para o uso como pavimento permeável, que pode ser construído com as seguintes tipologias: revestimentos em peças de concreto com juntas alargadas, revestimento em peças de concreto com áreas vazadas, revestimento de peças de concreto permeável, revestimento em placas de concreto permeável e revestimento de pavimento de concreto permeável (ABNT, 2015).

Segundo Lamb (2014), o uso do concreto permeável em pavimentos “[...] permite que a água das chuvas passe através dele e seja armazenada nas camadas inferiores, base e sub-base, até ser conduzida ao lençol freático por meio do subleito ou, então, ser levada ao sistema de drenagem da cidade". Deste modo, caracteriza-se como material apropriado para área que receberá as precipitações, evitando os alagamentos e realimentando o aquífero.

Vários são os estudos que tratam da incorporação dos subprodutos para produção de concreto permeável; Vidal (2014), que incorporou agregados reciclados de construção e demolição (RCD) para utilização em pavimentação permeável em ambiente urbano; Sandoval et al. (2019) que substituiram agregado graúdo por escória de forno elétrico (EFA) na produção do concreto permeável; e Schackow et al. 
(2020), produziram placas de concreto permeáveis com subprodutos da indústria de papel.

\section{MATERIAIS E MÉTODOS}

O presente trabalho foi desenvolvido no Instituto Federal de Alagoas (IFAL) e teve como objetivo caracterizar cascalho de perfuração de poços de petróleo provenientes da Bacia Sergipe-Alagoas (Figura 1). O material foi coletado no município de Carmópolis-SE, ainda úmido e acondicionado em sacos plásticos. Posteriormente passou por secagem ao sol por 8 horas para diminuição da umidade.

O método de pesquisa adotado consistiu no desenvolvimento experimental, ou seja, a pesquisa teve natureza tecnológica com abordagem quali-quantitativa e foi executada in vitro (Laboratório). 0 material coletado foi caracterizado pelas seguintes técnicas: Análise Granulométrica (AG); Microscopia Eletrônica de Varredura (MEV); Análise Química por Fluorescência de Raios X (FRX); Análise Mineralógica por Difração de Raios X (DRX) e Análises Térmicas.

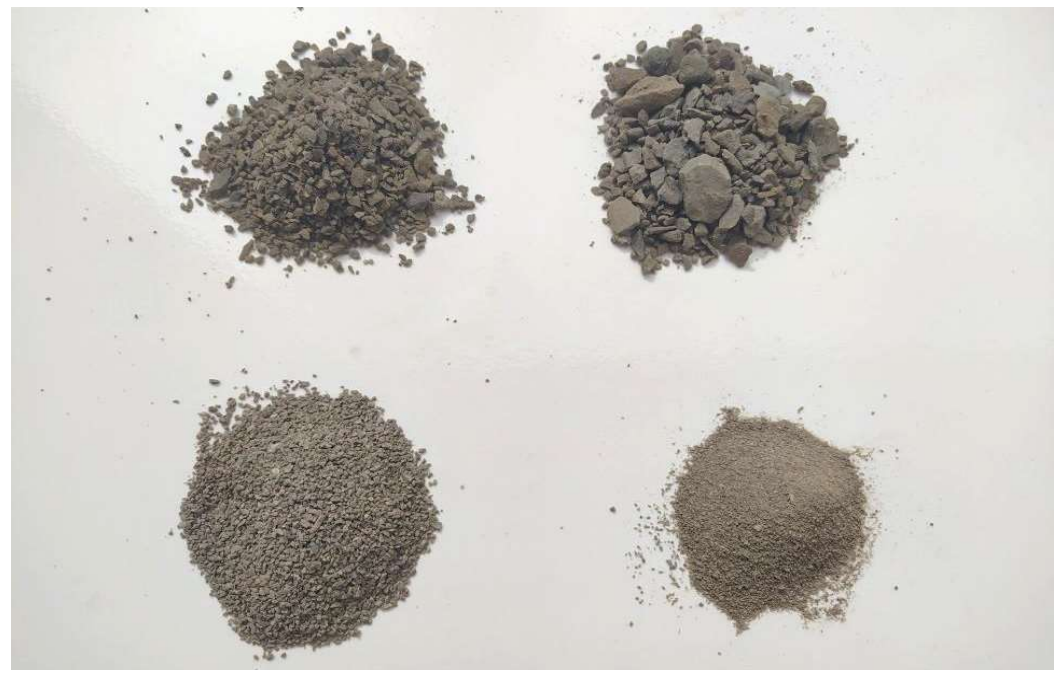

Figura 1: Cascalho de perfuração de poços de petróleo.

\section{Análise Granulométrica}

O ensaio de Granulometria teve como objetivo conhecer o tamanho dos grãos do solo, conforme a ABNT NBR 7181: Análise Granulométrica (ABNT, 2016), que apresenta o passo a passo necessário para se obter a curva granulométrica. O método utilizado no ensaio foi por peneiramento.

O primeiro passo realizado foi a separação das amostras de cascalho. Como o material foi coletado ainda úmido, foi necessário secagem ao ar por 8 horas para diminuição da umidade. Após a secagem, determinou-se a massa da amostra seca, que foi levada para peneiramento em peneira com espessura de 2,0 mm, para separação de material graúdo e miúdo.

A parte retida na peneira de $2,0 \mathrm{~mm}$ foi lavada a fim de eliminar o material fino aderente, sendo levada para secar em estufa à temperatura de $110^{\circ} \mathrm{C}$, até constância de massa. Esse material foi utilizado no peneiramento grosso que necessitou de agitador mecânico para peneiramento da amostra. O material retido foi lançado sobre as peneiras de $50 \mathrm{~mm}, 38 \mathrm{~mm}, 25 \mathrm{~mm}, 19 \mathrm{~mm}, 9,5 \mathrm{~mm}$ e $4,8 \mathrm{~mm}$.

Para o peneiramento do material passante na peneira de $2,0 \mathrm{~mm}$, foi necessário a lavagem do 
material na peneira de $0,075 \mathrm{~mm}$, vertendo-se água potável à baixa pressão. O material retido na peneira de $0,075 \mathrm{~mm}$ foi seco em estufa, à temperatura de $110^{\circ} \mathrm{C}$, até constância de massa; e, utilizando-se de agitador mecânico, executou-se peneiramento em malhas de 1,2 mm, 0,6 mm, 0,42 mm, 0,25 mm, 0,15 mm e 0,075 $\mathrm{mm}$. As massas retidas acumuladas em cada peneira foram anotadas.

O resultado final é apresentado graficamente, dispondo-se em abcissas os diâmetros das partículas, em escala logarítmica; e, em ordenadas, as porcentagens das partículas menores do que os diâmetros considerados, em escala aritmética.

O ensaio de granulometria foi realizado no laboratório de Construção Civil e Materiais do Instituto Federal de Alagoas, Campus Palmeira dos Índios.

\section{Microscopia Eletrônica de Varredura (MEV)}

A Microscopia Eletrônica de Varredura (MEV) consiste em ferramenta utilizada para a análise microestrutural de diversos materiais, e possibilita a análise de falhas, tamanho de partículas, estrutura e forma (COSTA, 2016). O ensaio foi necessário para identificar as particularidades do cascalho da Bacia Sergipe-Alagoas, possibilitando identificar a formação rochosa da camada de exploração.

As amostras estudadas foram peneiradas e selecionadas com diâmetro menor que 0,42 mm e submetidas no microscópio eletrônico de varredura de modelo MEV SSX 550 superscan - Shimadzu, no Laboratório de Química do Instituto Federal de Alagoas, Campus Maceió, com magnificação de 20x, 100x, 500x, 1000x, 2000x e 8000x.

Apesar de Fialho (2012), analisar o cascalho até magnificação máxima de 1000x, esse trabalho buscou aprofundar os aspectos microscópicos do subproduto para obter mais respostas quanto à estrutura molecular da região e amostra estudada.

\section{Fluorescência de Raios X (FRX)}

A espectrometria de fluorescência de Raios X (FRX) é a técnica não destrutiva que permite identificar os elementos presentes na amostra (análise qualitativa), assim como estabelecer a proporção de cada elemento. Por ser técnica instrumental muito reprodutível, rápida e precisa, a fluorescência de Raios X é o método mais usual para determinação da composição química dos materiais (OLIVEIRA, 2011).

A execução do ensaio mostrou-se importante por dois motivos: primeiro, para analisar os componentes da amostra, que permitissem avaliar os resultados obtidos nos testes de resistência e permeabilidade; e, para verificar a presença de componentes nocivos ao meio ambiente e aos usuários.

Nesse trabalho utilizou-se do espectrômetro por fluorescência de Raios X (EDX-700, Shimadzu) em atmosfera a vácuo, aplicando método semi-quantitativo para determinação dos elementos, realizado no Laboratório de Caracterização Estrutural dos Materiais da Universidade Federal do Rio Grande do Norte (UFRN). 


\section{Difração de Raios X (DRX)}

Dentre as várias técnicas de caracterização de materiais, a técnica de difração de Raios X (DRX) é o método mais abrangente para determinar a mineralogia dos materiais, não só devido à possibilidade da identificação das espécies minerais presentes, mas também por permitir estudar as características cristalográficas desses minerais. Dentre as principais vantagens da técnica, destacam-se a simplicidade e rapidez do método, a confiabilidade dos resultados e a possibilidade de análise quantitativa das fases cristalinas (SILVA et al., 2015).

As amostras estudadas por DRX foram classificadas por peneiramento na granulometria inferior a 0,075 mm, secas e analisadas em difratômetro de Raios X (XRD-6000, Shimadzu), localizado no Laboratório de Caracterização Estrutural dos Materiais da Universidade Federal do Rio Grande do Norte (UFRN), utilizando-se as seguintes condições: radiação de Cu-Ka $(\lambda=1,54056 \AA$, tensão de $40 \mathrm{kV}$, corrente de $30 \mathrm{~mA}$, ângulo de varredura $(2 \theta)$ de $10^{\circ}$ a $80^{\circ}$ ).

\section{Análises Térmicas}

A análise termogravimétrica é bastante difundida para complementar a caracterização de matériasprimas, buscando analisar quantitativamente o ganho e/ou perda de massa através das relações entre temperaturas e propriedades físicas. Assim, é possível estimar a vida útil dos materiais, bem como a estabilidade térmica. As principais técnicas termoanalíticas utilizadas em materiais são: Análise Termogravimétrica (TG) e Análise Térmica Diferencial (ADT). Essas análises têm o objetivo de avaliar fenômenos de transformação, tais como desidratações, decomposições, mudanças de fase e reações químicas acompanhadas de efeitos endotérmicos e exotérmicos (LIMA, 2010).

As amostras de cascalho foram preparadas com granulometria inferior a 0,075 $\mathrm{mm}$; posteriormente, a análise do cascalho de perfuração foi realizada no Laboratório de Propriedades Físicas dos Materiais Cerâmicos, usando o Shimadzu DTG-60, onde a amostra foi submetida à temperatura máxima de $1000{ }^{\circ} \mathrm{C}$, fluxo de gás de $50 \mathrm{~mL} / \mathrm{min}$, taxa de aquecimento de $10^{\circ} \mathrm{C} / \mathrm{min}$ em atmosfera de gás Argônio.

\section{RESULTADOS E DISCUSSÃO}

\section{Análise Granulométrica}

A Figura 2 apresenta a curva granulométrica do cascalho de perfuração de poços de petróleo da Bacia Sergipe-Alagoas. Comparando os resultados obtidos com a ABNT NBR 7211 - Agregados para concreto (2005), pode-se constatar que o material apresenta características de areia média, com módulo de finura igual a 2,87 .

Quando se analisou esses resultados com a ABNT NBR 6502 - Rochas e Solos (1995), que classifica os solos de acordo com a granulometria, observou-se que o material possui mais de $67 \%$ do volume entre 0,06 $\mathrm{mm}$ e $2,0 \mathrm{~mm}$, ou seja, a maior parte do material é caracterizado como areia, sendo cerca de $48 \%$ do volume total areia grossa, $17 \%$ areia média e, pouco mais de 2,0\%, areia fina. Identificou-se que, pouco mais de $31 \%$ 
da amostra, caracteriza-se como material granular, com granulometria maior que 2,0 $\mathrm{mm}$, sendo constatada a pequena quantidade de finos presente no material. Como o concreto permeável exige maior granulometria dos agregados, essa constatação mostra-se favorável para o desenvolvimento do produto, além de garantir maior utilização do subproduto (BATEZINI, 2013).

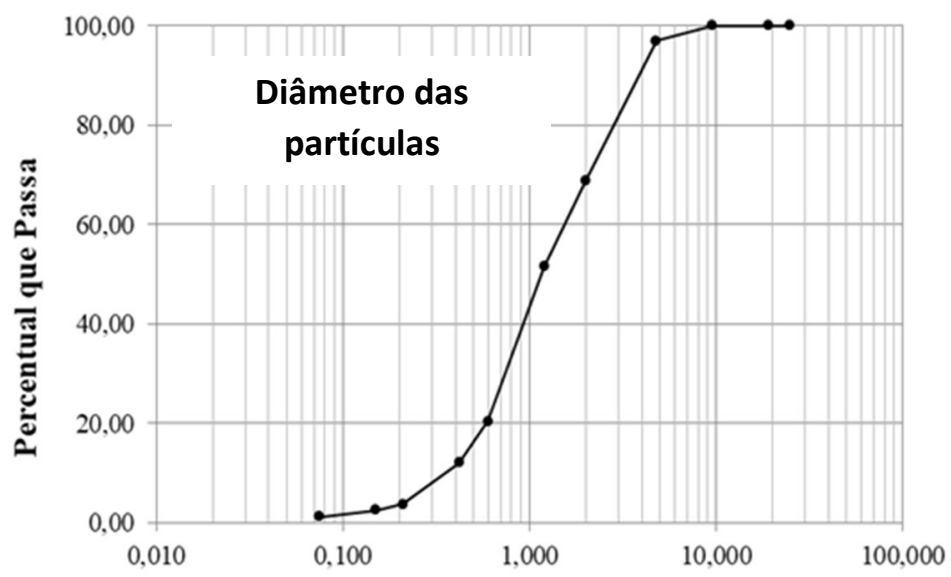

Figura 2: Análise granulométrica do cascalho.

\section{Microscopia Eletrônica de Varredura (MEV)}

Nas Figuras 3 e 4 identificou-se a não uniformidade das partículas de cascalho, bem como a aglomeração que forma espaços vazios e que não proporciona compactação entre eles. Além disso, não foi observada variação de granulometria, diferenciando dos resultados identificados por Marques (2015) e Acchar et al. (2016), que verificaram heterogeneidade entre partículas. Esse resultado corrobora com o ensaio de granulometria, onde mostra maior percentual de partículas entre os diâmetros de 0,6 mm e 4,8 $\mathrm{mm}$.
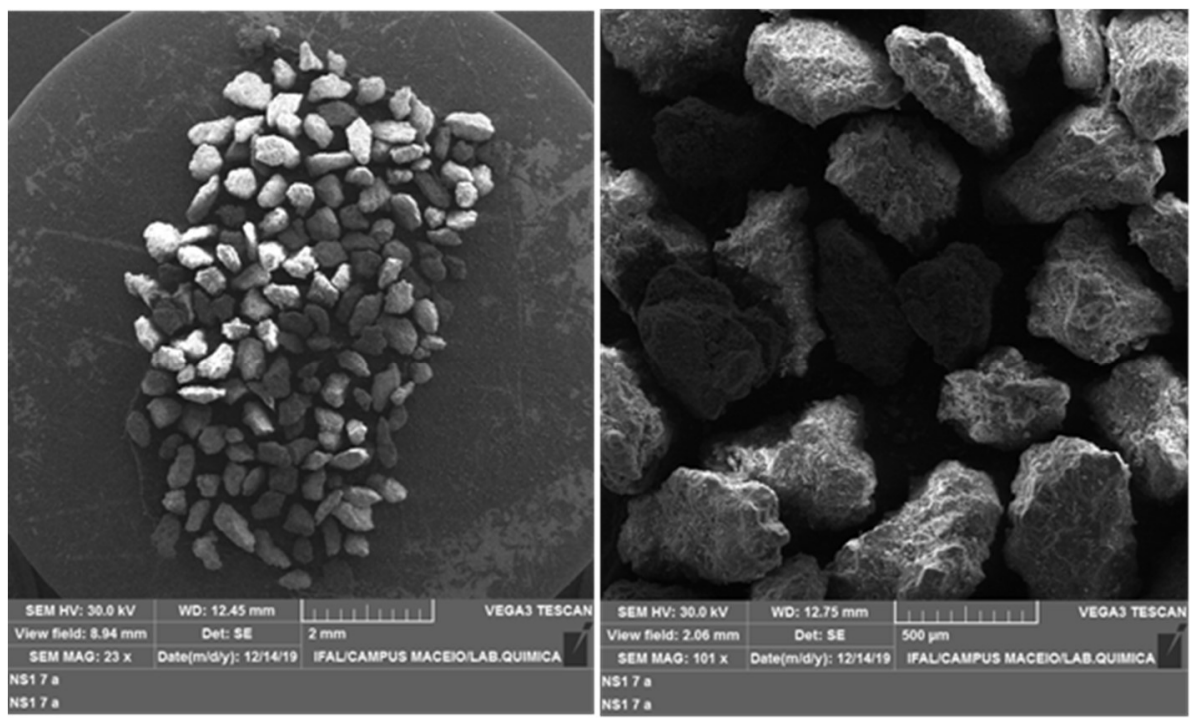

Figura 4: MEV das superfícies do cascalho com.

Quando se observou a Figura 5 e a Figura 6, percebeu-se a grande compactação dos grãos e ausência de vazios, confirmando as afirmações de Mota (2018) de que os cascalhos apresentam aspecto estrutural característico das argilas, com estrutura lamelar. Segundo Rossi (2017), essa formação rochosa é tipicamente 
encontrada em perfurações de poços nacionais e possuem aspecto maciço, compactado e endurecido.

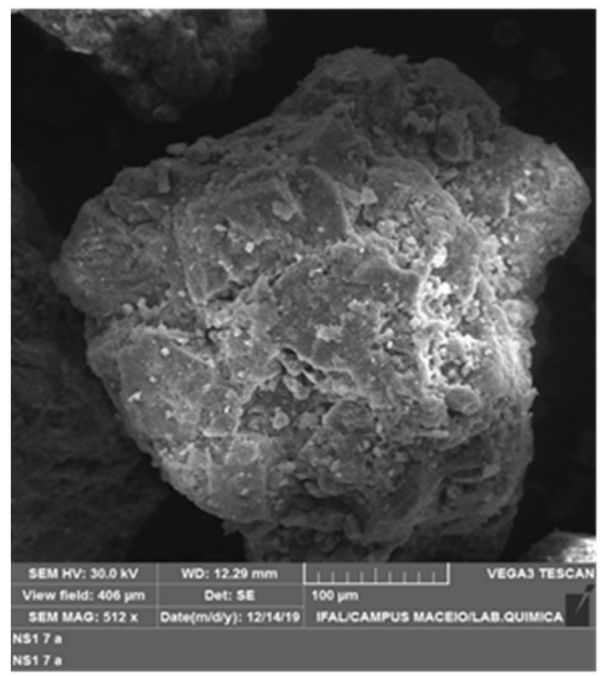

Figura 5: MEV das superfícies do cascalho com magnificação de 500x.

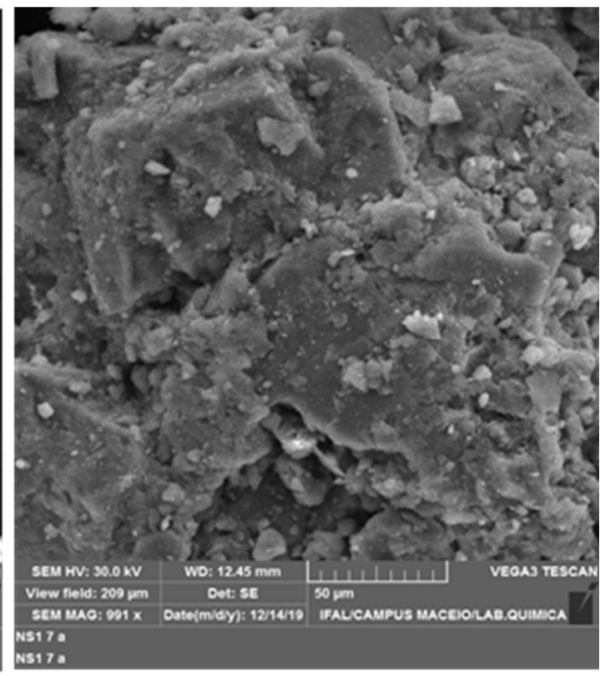

Figura 6: MEV das superfícies do cascalho com magnificação de 1000x.

Já na Figura 7 e Figura 8, constatou-se essa formação lamelar, que faz com que os grãos sejam constituídos por lâminas finas e paralelas.

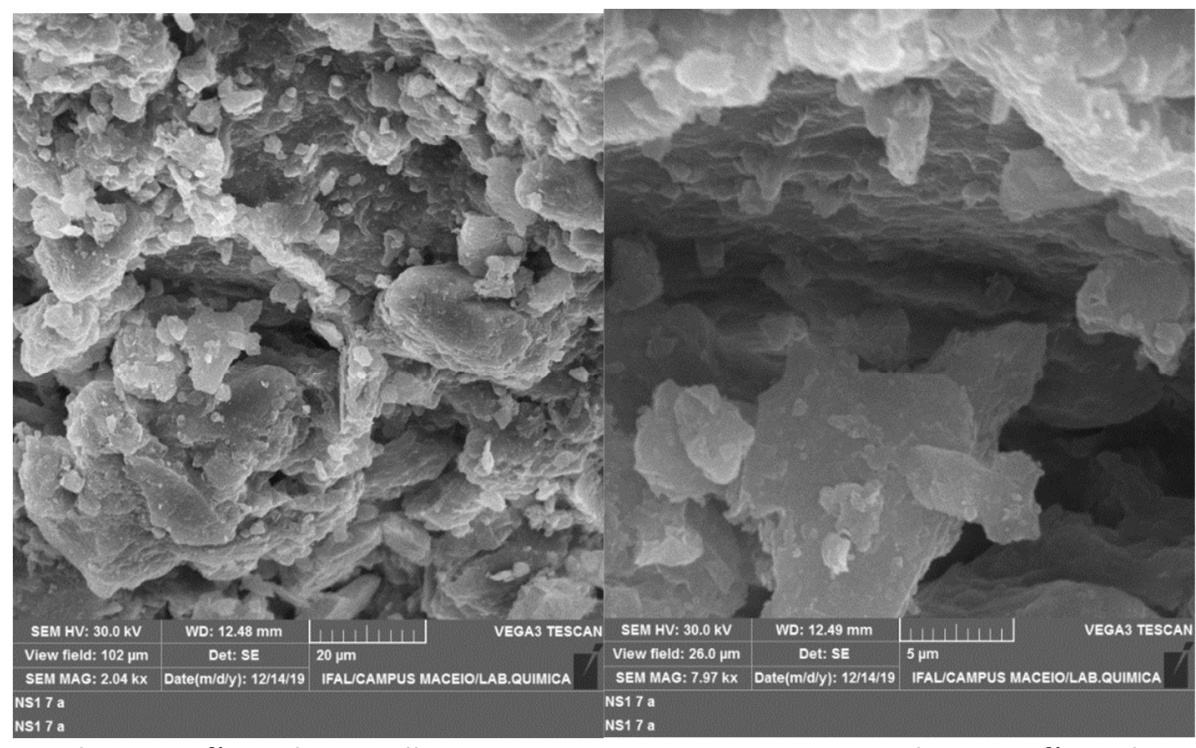

Figura 7: MEV das superfícies do cascalho com

Figura 8: MEV das superfícies do cascalho com magnificação de $2000 x$ magnificação de $8000 x$

\section{Fluorescência de Raios X (FRX)}

Na Tabela 1 observou-se que, na composição química do cascalho de perfuração, há ocorrência de alto teor de cálcio. Além disso, pôde-se identificar valores significativos de $\mathrm{Si}, \mathrm{Fe}, \mathrm{Mg}, \mathrm{Ag}, \mathrm{Al}$ e $\mathrm{K}$, o que também é apresentado em ensaios de fluorescência de cascalhos de perfuração provenientes de outras regiões do Brasil, como Fialho (2012), Marques (2015) e Fagundes (2018).

Tabela 1: Caracterização por FRX em cascalho.

\begin{tabular}{|l|l|l|l|l|l|l|l|l|l|l|l|l|l|}
\hline \multicolumn{1}{|l|}{ Fluorescência de Raios X (\%) } \\
\hline $\mathbf{C a}$ & $\mathbf{S i}$ & $\mathbf{F e}$ & $\mathbf{M g}$ & $\mathbf{A g}$ & $\mathbf{A l}$ & $\mathbf{K}$ & $\mathbf{S r}$ & $\mathbf{T i}$ & $\mathbf{S}$ & $\mathbf{Z n}$ & $\mathbf{M n}$ & $\mathbf{B r}$ & $\mathbf{C u}$ \\
\hline 65,89 & 8,75 & 6,81 & 6,58 & 3,69 & 3,63 & 2,45 & 0,62 & 0,48 & 0,33 & 0,27 & 0,24 & 0,17 & 0,09 \\
\hline
\end{tabular}


O alto teor de Ca é proveniente das rochas carbonáceas dos reservatórios petrolíferos, tanto da decomposição de organismos vivos como da precipitação química (SILVA, 2014).

\section{Difração de Raios X (DRX)}

Na Figura 9 apresenta-se o difratograma de Raios $X$ do cascalho, onde foram identificados picos característicos das fases dolomita $\left(\mathrm{CaMg}\left(\mathrm{CO}_{3}\right)_{2}\right)$, quartzo $\left(\mathrm{SiO}_{2}\right)$ e calcita $\left(\mathrm{CaCO}_{3}\right)$. Observou-se que a dolomita é a fase cristalina predominante, corroborando com os resultados apresentados na análise química por fluorescência, onde foi obtida a concentração de 65,89\% de cálcio.

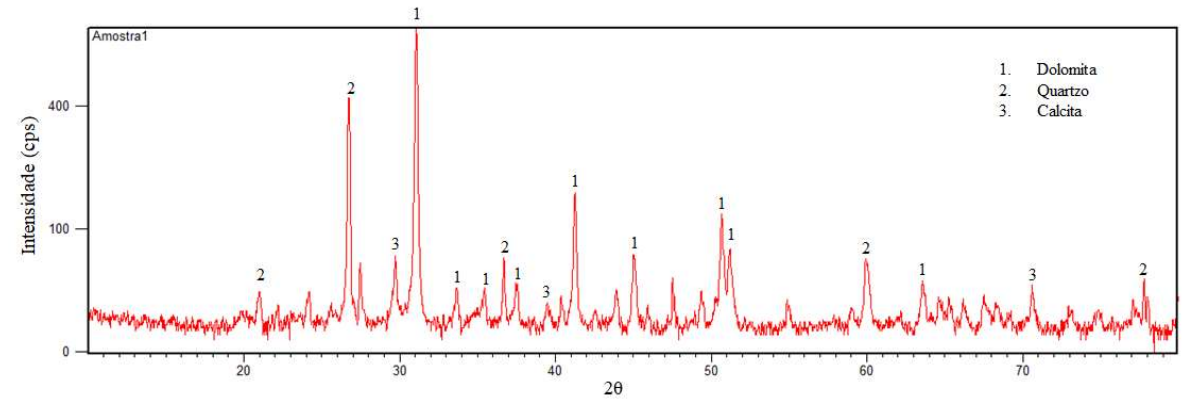

Figura 9: Caracterização por DRX.

Segundo Petri Júnior (2014), mesmo que em algumas fases da perfuração dos poços se encontrem rochas ígneas e até metamórficas, a teoria mais aceita sobre a formação do petróleo é que ele se origina a partir da decomposição de matéria orgânica junto com sedimentos, durante a formação das bacias sedimentares, isso explica o alto teor de dolomita na amostra.

\section{Análises Térmicas}

A Figura 10 apresenta a curva termogravimétrica do cascalho de perfuração. Foi possível verificar que o cascalho perde em torno de $14 \%$ de massa à medida que a temperatura se eleva até 1000 ㄷ. Observouse duas etapas de perda, a primeira ocorre na faixa de temperatura entre $100^{\circ} \mathrm{Ce} 500^{\circ} \mathrm{C}$ e pode ser atribuída à desidratação dos compostos orgânicos voláteis, provenientes do hidrocarboneto incorporados ao cascalho de perfuração e a presença de água (MARQUES, 2015). Esses resultados mostram-se favoráveis para o fim de aplicação dos cascalhos, visto que apresenta baixo percentual de perda, principalmente na faixa de temperatura entre $0^{\circ} \mathrm{C}$ a $100^{\circ} \mathrm{C}$.

A segunda etapa de perda de massa ocorre na faixa de temperatura entre $500{ }^{\circ} \mathrm{C}$ e $600{ }^{\circ} \mathrm{C}$ que pode estar relacionada a estabilização do composto (MARQUES, 2015). Observou-se que em torno de 600 ㄷ ocorre a inversão térmica onde o quartzo passa da fase $\alpha$ para fase $\beta$. A partir de $600 \cong \mathrm{C}$ notou-se estabilização das perdas. 


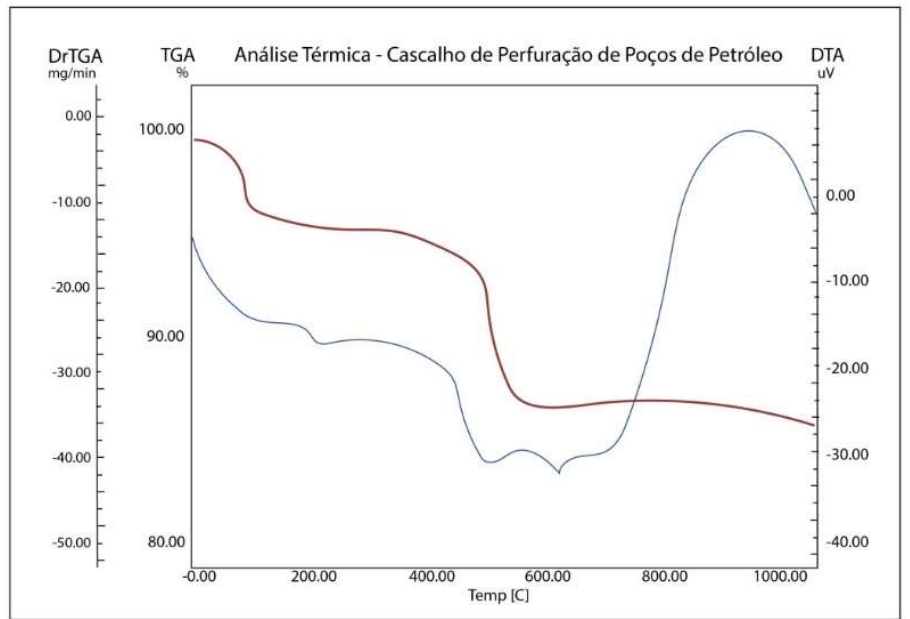

Figura 10: Análise Térmica do cascalho de perfuração.

\section{CONCLUSÕES}

Diante dos resultados apresentados pode-se concluir que: O cascalho de perfuração de poços de petróleo apresentou módulo de finura igual a 2,87, que o caracteriza como areia média; Observou-se, pelas imagens geradas no MEV, que o cascalho apresenta aspecto estrutural característico das argilas, com estrutura lamelar, tipicamente encontrada em perfurações de poços nacionais, com aspecto maciço, compactado e endurecido; Na composição química do cascalho, há ocorrência de alto teor de $\mathrm{Ca}$, ultrapassando o percentual de $65 \%$ da amostra analisada; Na difração de raios $\mathrm{X}$ do cascalho, foram identificados picos característicos das fases dolomita $\left(\mathrm{CaMg}\left(\mathrm{CO}_{3}\right)_{2}\right)$, quartzo $\left(\mathrm{SiO}_{2}\right)$ e calcita $\left(\mathrm{CaCO}_{3}\right)$. Observou-se que a dolomita é a fase cristalina predominante, corroborando com os resultados apresentados na análise química por fluorescência, onde foi apresentada concentração de 65,89\% de cálcio;

A caracterização do cascalho proveniente da perfuração de poços de petróleo da Bacia SergipeAlagoas proporcionou visão mais ampla do cascalho enquanto subproduto, sendo possível reaproveitá-lo para estudos em diferentes incorporações. Com os dados obtidos foi possível inserir o cascalho na produção de concretos permeáveis. Como resultado da incorporação verificou-se que o concreto pode ser utilizado para tráfego de pedestres, apresentando resistência e permeabilidade satisfatórias.

\section{REFERÊNCIAS}

ABNT. Associação Brasileira de Normas Técnicas. NBR 6502:1995: Rochas e Solos. São Paulo: ABNT, 1995.

ABNT. Associação Brasileira de Normas Técnicas. NBR 7181: Solo: Análise granulométrica. Método de ensaio. São Paulo: ABNT, 2016.

ABNT. Associação Brasileira de Normas Técnicas. NBR 16416:2015: Pavimentos permeáveis de concreto: Requisitos e procedimentos. Rio de Janeiro: ABNT, 2015.

ACCHAR, W.; MARQUES, S. K. J.. Ecological soil-cement bricks from waste materials. Springer International Publishing, 2016.

ALMEIDA NETO, J. B.. Aproveitamento do cascalho de perfuração de poços para elaboração de pasta de cimentação primária. Tese (Doutorado em Desenvolvimento e Meio Ambiente) - Universidade Federal de Sergipe, São Cristóvão, 2017.

ALMEIDA, P. C.. Análise Técnico-ambiental de Alternativas de Processamento de Cascalho de Perfuração Offshore. Dissertação (Mestrado) - Universidade Federal do Rio de Janeiro, Rio de Janeiro, 2016.

BANDEIRA, R. A. F.. Uso de cascalho de perfuração de poços de petróleo na confecção de CBUQ (concreto betuminoso usinado a quente). Tese (Doutorado) - Universidade Federal do Rio Grande do Norte, Natal, 2019.

BATEZINI, R.. Estudo preliminar de concretos permeáveis 
como revestimento de pavimentos para áreas de veículos leves. Dissertação (Mestrado) - Escola Politécnica da Universidade de São Paulo, São Paulo, 2013.

COSTA, F. R. T.. Microscopia Eletrônica de Varreduras: potencialidades e aplicações. Monografia (Bacharelado) Universidade Federal do São Luís, São Luís, 2016.

FAGUNDES, T. B.. Caracterização de cascalhos de perfuração de poços de petróleo por técnicas analíticas instrumentais. Dissertação (Mestrado) - Universidade de São Paulo, São Paulo, 2018

FIALHO, P. F.. Cascalho de perfuração de poços de petróleo e gás. Estudo do potencial de aplicação em concreto. Dissertação (Mestrado em Engenharia Civil) - Universidade Federal do Espírito Santo, Vitória, 2012.

JOHN, V. M.. Reciclagem de resíduos na construção civil: contribuição para metodologia de pesquisa e desenvolvimento. Tese (Doutorado) - Escola Politécnica da Universidade de São Paulo, São Paulo, 2000.

LAMB, G. S.. Desenvolvimento e análise do desempenho de elementos de drenagem fabricados em concreto permeável. Dissertação (Mestrado em Engenharia Civil) Universidade Federal do Rio Grande do Sul, Porto Alegre, 2014.

LEITE, D. A. B; ARAÚJO, J. B.. Aspectos da política pública municipal de resíduos sólidos em Fortaleza. In: ENCONTRO DA ASSOCIAÇÃO NACIONAL DE PÓS GRADUAÇÃO E PESQUISA EM AMBIENTE E SOCIEDADE, 3. Anais. Brasília, 2006. p.20.

LOMASSO, A. L.; SANTOS, B. R.; ANJOS, F. A. S.; ANDRADE, J. C.; SILVA, L. A.; SANTOS, Q. R.; CARVALHO, A. C. M.. Benefícios e Desafios na implementação da reciclagem: um estudo de caso no centro mineiro de referência em resíduos (CMRR). Revista Pensar Gestão e Administração, v.3, n.2, 2015.

MARQUES, S. K. J.. Produção de tijolos resíduo-cimento usando cascalho de perfuração e cinzas de bagaço de canade-açúcar. Tese (Doutorado) - Universidade Federal do Rio Grande do Norte, Natal, 2015.

MARTINS, S. S. S.; AZEVEDO, M. O.; SILVA, M. P.; SILVA, V. P. Produção de petróleo e impactos ambientais: algumas considerações. Revista Holos, v.6, 2015. DOI: http://doi.org/10.15628/holos.2015.2201

MENESES, C. G.; PAULA, G. A.. Avaliação do resíduo de cascalho de perfuração de poços de petróleo da bacia potiguar e alternativas para sua destinação e reaproveitamento. Revista RUnPetro, v.3, n.1, p.29-38, 2015.

MOTA, A. C. S.. Propriedades dielétricas e cinética de secagem de cascalhos de perfuração de poços de petróleo e gás utilizando micro-ondas. Dissertação (Mestrado) Universidade Federal de Uberlândia, Uberlândia, 2018.

NICOLLI, D.; SOARES, C. B. P.. Avaliação da dispersão do cascalho de perfuração lançado em águas profundas. UNICAMP, 2010.
OLIVEIRA, E. A.. Confiabilidade metrológica na determinação de espécies químicas em materiais siderúrgicos por espectrometria de fluorescência de raiosX. Dissertação (Mestrado) - Pontifícia Universidade Católica do Rio de Janeiro, Rio de janeiro, 2011.

ORTIZ NETO, J. B.; COSTA, A. J. D.. A Petrobrás e a exploração de petróleo offshore no Brasil: um approach evolucionário. Revista Brasileira de Economia, Rio de Janeiro, v.6, n.1, 2007. DOI: http://dx.doi.org/10.1590/S003471402007000100006

ORTIZ NETO, J. B.; SHIMA, W. T.. Trajetórias tecnológicas no segmento offshore: ambiente e oportunidades. Revista Economia Contemporânea, Rio de Janeiro, v.12, n.2, 2008. DOI: http://dx.doi.org/10.1590/S1415-98482008000200005

PETRI JUNIOR, I.. Formação do petróleo é que ele se origina a partir da decomposição de matéria orgânica junto com sedimentos. Dissertação (Mestrado) - Universidade Federal de Uberlândia, Uberlândia, 2014.

PIRES, P. J. M.. Utilização de Cascalho de Perfuração de Poços de Petróleo para a Produção de Cerâmica Vermelha. Tese (Doutorado) - Pontifícia Universidade Católica do Rio de Janeiro, Rio de Janeiro, 2009.

PEREIRA, M. S.. Caracterização de cascalho e lama de perfuração ao longo do processo de controle de sólidos em sondas de petróleo e gás. Dissertação (Mestrado) Universidade Federal de Uberlândia, Uberlândia, 2010.

RIBEIRO, L. S.. Uso de água produzida na formulação de fluídos de perfuração. Dissertação (Mestrado) Universidade Federal do Rio Grande do Norte, Natal, 2015.

ROCHA, B. A. B.; LIMA, F. R. S.; WALDMAN, R. L.. Mudanças no papel do indivíduo pós-revolução industrial e o mercado de trabalho na sociedade da informação. Revista Pensamento Jurídico, v.14, n.1, 2020.

ROSSI, A. S.. Cinética de aquecimento e secagem, propriedades dielétricas e simulação computacional aplicado ao tratamento de cascalho de perfuração por micro-ondas. Tese (Doutorado) - Universidade Federal de Uberlândia, Uberlândia, 2017.

SANDOVAL, G. F. B.; GALOBARDES, I.; DIAS, C.; CAMPOS, A.; TORALLES, B. M.. Pervious concrete made with electric furnace slag (FEA): mechanical and hydraulic properties. IBRACON, São Paulo, v.12, n.3, p.590-607, 2019. DOI: http://doi.org/10.1590/s1983-41952019000300009

SCHACKOW, A.; EFFTING, C.; BARROS, V. G.; GOMES, I. R.; DALANDRÉA, M. S.. Permeable concrete plates with wastes from the paper industry: Reduction of surface flow and possible applications. Construction and Building Materials, Joinville, v.250, 2020. DOI: http://doi.org/10.1016/i.conbuildmat.2020.118896

SHON, C. S.; ESTAKHRI, C. K.; LEE, D.; ZHANG, D.. Evaluating feasibility of modified drilling waste materials in flexible base course construction. Construction and Building Materials, v.116, p.79-86, 2016. DOI:

http://doi.org/10.1016/i.conbuildmat.2016.04.100

SILVA, B. J. B.; SILVA, A. O. S.; NETO, P. P. M.; COSTA, T. P. 
M.; JÚNIOR, L. V. S.; RIBEIRO, L. M. O.; ALENCAR, S. L.; SILVA, A. E.; SANTOS, R. B.. Análise quantitativa das zeólitas ferrierita, ZSM-5 e mordenita presentes em amostras sintetizadas. Cerâmica, São Paulo, v.61, n.357, 2015. DOI: http://dx.doi.org/10.1590/0366-69132015613571842

SILVA, C. H.. Influência da Incorporação de Sólidos nas Propriedades de Fluidos de Perfuração Sintéticos.

Dissertação (Mestrado) - Universidade Federal de Campina Grande, Campina Grande, 2014.
SOUZA, O.; OLIVEIRA, L. J.. Globalização e relações de consumo: servidão moderna e degradação ambiental. Revista Direito Ambiental e sociedade, v.6, n.2, p.156-178, 2016.

VIDAL, A. S.. Caracterização de concreto permeável produzido com agregados reciclados de construção e demolição para utilização em pavimentação permeável em ambiente urbano. Dissertação (Mestrado) - Universidade Federal do Rio de Janeiro, Rio de Janeiro, 2014

A CBPC - Companhia Brasileira de Produção Científica (CNPJ: 11.221.422/0001-03) detém os direitos materiais desta publicação. Os direitos referem-se à publicação do trabalho em qualquer parte do mundo, incluindo os direitos às renovações, expansões e disseminações da contribuição, bem como outros direitos subsidiários. Todos os trabalhos publicados eletronicamente poderão posteriormente ser publicados em coletâneas impressas sob coordenação da Sustenere Publishing, da Companhia Brasileira de Produção Científica e seus parceiros autorizados. Os (as) autores (as) preservam os direitos autorais, mas não têm permissão para a publicação da contribuição em outro meio, impresso ou digital, em português ou em tradução. 